13 West KM. Epidemiology of diabetes and its rascular lesions. New York: Elsevier, 1978:221-4

14 Bengstrom C, Rybo G, Westerberg H. Number of pregnancies, use of oral contraceptives and menopausal age in women with ischaemic heart disease compared to a population sample of women. Acta Med Scand [Suppl] 1973;549:75-81.

15 Brinton LA, Hamman RF, Huggins GR, et al. Sexual and reproductive risk factors for invasive squamous cell cervical cancer. $7 N C I$ 1987;79:23-30

16 Beral V. Parity and susceptibility to cancer. In: Fetal antigens and cancer. London: Pitman, 1983:182-203. (Ciba Foundation Symposium 96.)

17 Kvale G, Heuch I, Elde GE. A prospective study of reproductive factors and breast cancer. I. Parity. Am J Epidemiol 1987:126:831-41.

18 Scott JS Sex hormones and gynaecologicat ancer.BrMed f 1982:284:1657-8.
19 Fraga A, Mintz G, Orozoco J, Orozoco JH. Sterility and fertility rates, fetal wastage and maternal morbidity in systemic lupus erythematosus. 7 Rheumatol 1974;1:293-8.

20 Cartwright A. How many children? London: Routledge and Kegan Paul, 1976:96.

21 Dorn H. Cancer and marital status. Hum Biol 1943;15:73-9.

22 Heliovaara M, Aromaa A. Parity and obesity. F Epidemiol Community Health 1981;35:197-9.

23 Freinkel N. Of pregnancy and progeny. Diabetes 1980;29:1023-35.

24 Oliver MF, Boyd GS. Plasma lipid and serum lipoprotein patterns during pregnancy and puerperium. Clin $S_{c i} 1985 ; 14: 15-23$.

(Accepled 10 Mav 1988

\section{Predictive value of oxygen saturation in emergency evaluation of asthmatic children}

\author{
Gary C Geelhoed, Louis I Landau, \\ Peter N LeSouëf
}

Princess Margaret Hospital for Children,

Box D184 GPO, Perth, Western Australia

Australia 6008

Gary C Geelhoed, FRACP, research fellow in respiratory medicine

Louis I Landau, FRACP, professor of paediatrics

Peter N LeSouëf, FRACP, director, department of

respiratory medicine

Correspondence to:

Dr Geelhoed.

Asthma is the most common respiratory condition in patients who present to emergency departments.' As hypoxia is common in asthma ${ }^{2}$ we reasoned that the severity of an attack might be reflected by the degree of arterial oxygen saturation. This may now be measured simply, non-invasively, and reliably by pulse oximetry. ${ }^{3+}$

We undertook this study to assess the clinical usefulness of oxygen saturation as an objective measure of the-severity of asthma in the emergency department and as a predictor of outcome.

\section{Patients, methods, and results}

We studied 52 patients $(31$ male, 21 female; mean age 6 (range 2-14) years) who presented to an emergency department with acute asthma. All received salbutamol aerosol $(0.03 \mathrm{ml} / \mathrm{kg}$ of a $0.5 \%$ solution to a maximum of $1 \mathrm{ml}$ made up to $2 \mathrm{ml}$ with normal saline) given by an Inspiron 002220 nebuliser driven by 6 litres of air a minute. Assessments and treatments were performed by staff unaware of the results of measuring arterial oxygen saturation. Baseline saturation and saturation at 30 minutes after nebulisation started were measured with an Ohmeda Biox III oximeter (Ohmeda Bioximetry Technology Inc, Boulder, Colorado).

Parents of children who were sent home were contacted five days later and asked if their child had presented again with asthma for medical care. If the answer was "no" parents were asked: "Were you happy with your child's condition following your visit to the emergency department?" For those sent home a favourable course was defined as not presenting again for medical care and parents answering "yes" to the second question. We noted those children admitted who received intravenous treatment. Results are reported as means (SD) and were analysed by Student's $t$ test.

Of the 24 children sent home, eight presented again for medical care, and the parents of three others were not happy with their child's condition after leaving the emergency department. Figure (a) shows the arterial oxygen saturation at presentation for all these groups. The initial saturation of those who presented once $(93.5(4.4) \%)$ was higher than that of those who presented twice $(89 \cdot 4(2 \cdot 0) \%)(\mathrm{p}<0.05)$. At 30 minutes no difference was noted between those presenting once $(93.9(2.8) \%)$ and those presenting twice $(92.6$ $(1.5) \%$ ) (figure (b)). Only those who presented twice showed a significant increase in arterial oxygen saturation from baseline to 30 minutes after nebulisation $(\mathrm{p}<0.01)$.

The initial arterial oxygen saturation was highly predictive of outcome. Saturation of $91 \%$ was found to discriminate between a favourable and an unfavour-
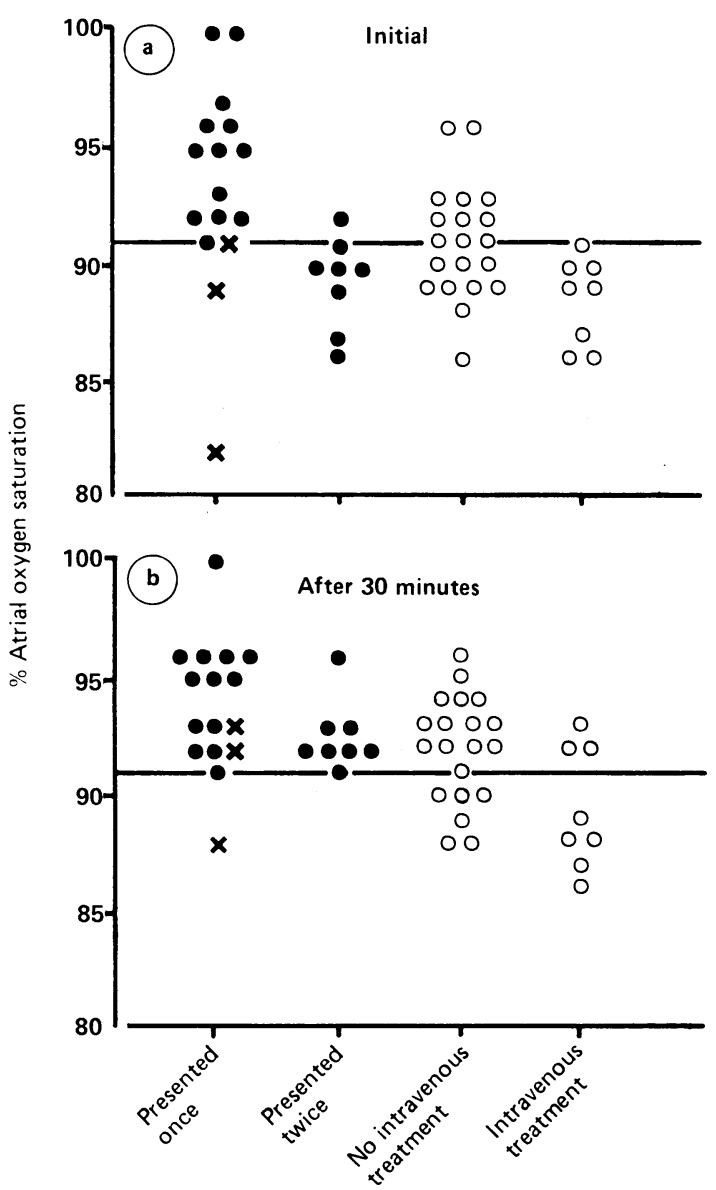

Arterial oxygen saturation of 52 children (a) before and (b) 30 minutes after nebulisation. $\quad=$ Sent home. $\bigcirc=$ Admitted. $\times=$ Parents unhappy

able outcome. Of 13 children sent home with an initial saturation of greater than $91 \%$, only one presented again. Eleven children who had an initial saturation of $91 \%$ or less were sent home; all but one of these children had an unfavourable outcome.

\section{Comment}

Several important clinical points arise from these data. Firstly, patients who have low initial arterial oxygen saturation, even if they respond to salbutamol, should always be treated with concern. Some of these children may be better managed as inpatients or need additional drug treatment if sent home. Secondly, an increase in saturation in response to nebulised salbutamol in the emergency department does not necessarily correlate well with a good outcome.

We emphasise that the initial saturation should not be used as the sole criterion for judging the need for admission, as some children who have severe asthma are often admitted for stabilisation of management. In our study the group who showed the best response to bronchodilator treatment had a poor outcome. We therefore suggest that when judging the severity of an asthmatic attack in children doctors should give more consideration to the initial arterial oxygen saturation 
than to the rise in saturation after bronchodilator treatment.

Oximetry seems to provide a rapid and accurate assessment of acute childhood asthma in the emergency department.

This study was supported by the Asthma Foundation of Western Australia and the TVW Telethon Foundation.
1 Lee DA, W'inslow NR, Speight ANP, Hey EN. Prevalence and spectrum of asthma in childhoed. Br. Hed F 1983;286:1258-60.

2 McFadden LR, Lyons HA. Arterial-blood gas tension in asthma. $N$ Engl.7 Med $1968 ; 278: 1027-32$

3 Burki NK, Albert RK. Noninvasive monitoring of arterial blend gases: a repor of the ACCP section on respiratory pathophysiology. Chest 1983;83:666-70. 4 Rebuck AS, Chapman KR, D'Urzo A. The accuracy and response characteristics of a simplified ear oximeter. Chest 1983:83:860-4.

Accepted 12 April 1988
Gastroenterology Unit, Department of Medicine, Westmead Hospital, Westmead, NSW 2145, Australia P I Craig, FRACP, research fellow

PE Gillespie, FRACP, consultant gastroenterologist

Correspondence and reprint requests to: Dr Craig.

\section{Through the endoscope balloon dilatation of benign gastric outlet obstruction}

\section{P I Craig, P E Gillespie}

Traditionally benign gastric outlet obstruction that has failed to settle with medical treatment has been corrected surgically.' The recent development of wire guided hydrostatic balloon dilators has offered an alternative to surgery, particularly in high risk patients. ${ }^{2}$ This technique, however, requires radiological control and fails in $26 \%$ of patients because of difficulties in positioning both the guidewire and subsequently the dilator through the stricture.' We report a recently developed endoscopic technique for managing this problem which does not require guidewire placement.

\section{Methods and results}

The procedure is usually performed during outpatient endoscopy. The system is composed of a $180 \mathrm{~cm}$ polyethylene catheter with a built in guidewire (Microvasive, Mass, USA). Near the tip is a low compliance balloon $2 \mathrm{~cm}$ long. A $10 \mathrm{ml}$ syringe is used to inflate the balloon with water; the inflation pressure is monitored by a gauge connected to the catheter. Balloon catheters of increasing diameter $(8-15 \mathrm{~mm})$ are introduced through a $2.8 \mathrm{~mm}$ or larger endoscope biopsy channel. They are positioned to lie across the stricture. The balloon is then inflated, held for 60 seconds, pulled back into the stomach, and then deflated. The procedure is repeated until the stricture is dilated to $15 \mathrm{~mm}$.

From June 1986 to October 198714 patients with benign gastric outlet obstruction were studied prospectively. Their mean age was 68 , and seven were either aged over 75 or had an associated serious illness which would have made an operation hazardous. Thirteen patients had symptoms, while one asymptomatic patient was found to have a pyloric stenosis during a procedure indicated for endoscopic sphincterotomy. Ten patients underwent a barium meal examination before dilatation. All had evidence of gastric outlet narrowing, and eight had gastric dilatation and barium retention. The diagnosis was confirmed in all patients by the failure to pass an $11 \mathrm{~mm}$ diameter endoscope through the stricture. Eleven patients had pyloric stenosis, two postbulbar duodenal obstruction, and one stenosis of both outlets of a Billroth 2 gastroenterostomy.

Dilatation was eventually successful in 13 of the 14 patients, as assessed by the passage of a therapeutic endoscope (outer diameter 11.5 or $12.8 \mathrm{~mm}$ ) through the stricture and improvement in symptoms. There were no complications. Patients required a mean of 1.9 (range 1-5) dilatation sessions, at six week intervals, to achieve a successful result. In the one failure the catheter could not be positioned through an eccentric stenosed pylorus. In seven patients a repeat barium meal three-12 weeks after successful dilatation showed

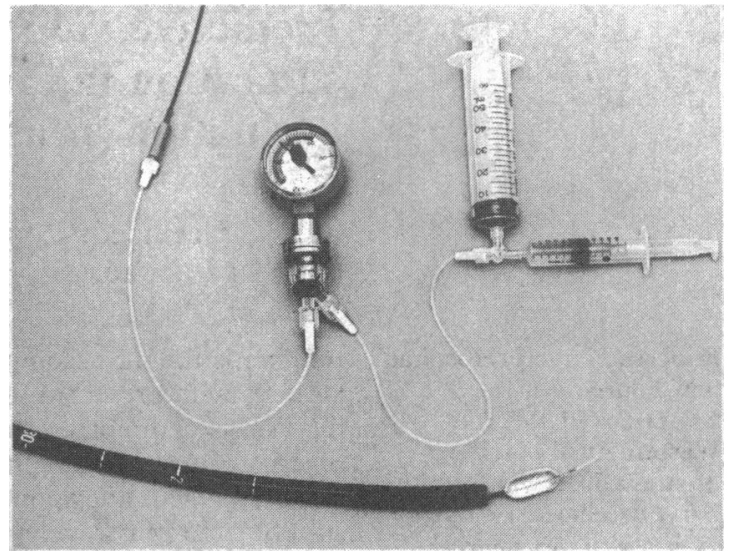

Inflated balloon catheter with pressure gauge and syringe assembly

improvement. Eleven of the successfully treated patients have continued long term treatment with ranitidine and the two others have remained well after only eight weeks' treatment. Despite symptomatic improvement further dilatations (mean 1.4) were performed in five patients because of endoscopic evidence of restenosis. The mean time of follow up was 10 (range 1-16) months. Four of the six patients followed up for over a year after successful dilatation remained well without recurrence, while two others required periodic dilatations to maintain endoscopic patency.

\section{Comment}

Earlier studies using wire guided hydrostatic balloon catheters resulted in symptomatic improvement in $67-83 \%$ of patients in whom stenoses were dilated. ${ }^{2.5}$ In contrast, $93 \%$ of all patients ( $100 \%$ of dilated patients) in this study achieved both symptomatic and objective evidence of improvement. The procedure was well tolerated and is technically easier to perform than wire guided dilatation. The correct timing for follow up dilatations is uncertain. Periodic procedures may be unnecessary for asymptomatic patients with endoscopic evidence of restenosis whereas symptomatic patients requiring repeated dilatations may eventually need surgery. The short term results support the use of this technique in high risk patients, but longer follow up is needed to assess its place in the definitive management of gastric outlet obstruction.

We thank Dr P N Francis for allowing us to include his patient.

1 Jaffin BW, Kaye MD. The prognosis of gastric outlet obstruction. Ann Surg 1985;201:176-9.

2 Benjamin SB, Glass RL, Cattau EL, Miller WB. Preliminary experience with balloon dilation of the pylorus. (iastroimest Endosc 1984;30:93-5.

3 Lindor $\mathrm{KD}$, Ott BJ, Hughes RW. Balloon dilatation of upper digestive tract strictures. (Gastroenterolog' 1985;89:545-8.

+ Hogan RB, Hamilton JK, Polter DE. Preliminary experience with hydrostatic balloon dilation of gastric outlet obstruction. Gastrointest Endosc 1986;32: $71-4$.

5 Kozarek RA. Hvdrostatic balleon dilation of gastrointestinal stenoses: a national survev. (justrointest Endosc 1986;32:15-9.

Accepted 5 Mav 1988 